\title{
Enformasyondan Bilgi'ye: Üniversite Öğrencileri Haberleri Sosyal Medyadan mı Öğrenir?
}

\author{
Birgül Taşdelen ${ }^{a, b}$
}

Özet

Çevrimiçi ortamların etkili bir iletişim aracı olarak yükselişi, habere ulaşma, tüketme ve paylaşma şeklini kökten değiştirdi. Haber platformu olarak sosyal medyanın yükselişi, bilgiye erişim ve katılım deneyimlerimizi de zenginleştirmiştir. Bu çalışma, genç kullanıcıların sosyal medyada haber tüketim sürecini Eveland'in Bilişsel Arabuluculuk modeli ile incelemektedir. Sosyal medyada habere rastlantısal maruz kalınması, paylaşılan haber içeriğine katılım, bilişsel ayrıntılandırma ve güncel olaylar bilgisi arasındaki ilişkileri ortaya çıkarmayı amaçlayan bu araştırma, 402 kişiyle veri toplama aracı kullanılarak gerçekleştirilmiştir. Araştırmadan elde edilen sonuçlara göre, genç kullanıcıların çoğu, çevrimiçi erişim gerektiren dijital ortamlarla bağlantılarının bir parçası olarak sosyal medyada rastladıkları haberlere dikkat etmektedir. Ayrıca sonuçlar, pasif olarak habere maruz kalan genç kullanıcıları da dahil etme becerisine sahip sosyal medyanın, haber ve bilgi kullanımı arasındaki ilişkiye aracılık ettiğini ortaya koymaktadır.
Anahtar Kelimeler

Sosyal Medya

Haber Tüketimi

Bilişsel Arabuluculuk Modeli

Gazetecilik

Makale Hakkında

Geliş Tarihi: 16.01.2020

Kabul Tarihi: 19.08.2020

Doi: 10.18026/cbayarsos.676339

\section{From Information to Knowledge: Do University Students Learn News from Social Media?}

\begin{abstract}
The rise of online environments as an effective means of communication has radically changed the way in which news is accessed, consumed and shared. The rise of social media as a news-platform enriches our experiences of access to information and participation. This study examines the news consumption process of young users on social media with Eveland's Cognitive Mediation Model. This study aimed to reveal the relationship between random media exposure, participation in shared news content, cognitive refinement, and current affairs information and this research was carried out using 402 data collection tool. According to the results of the research, most young users pay attention to the news they encounter on social media as a part of their connection to digital environments that require online access. The results also show that social media capable of involving young users who are passively exposed to news mediate the relationship between news and information use.
\end{abstract}

Keywords

Social Media

News consumption

Cognitive Mediation Model

Journalism

About Article

Received: 16.01 .2020

Accepted: 19.08.2020

Doi: 10.18026/cbayarsos.676339

a birgultasdelen@gmail.com

b Dr. Öğr. Üyesi, Gümüşhane Üniveritesi/İletişim Fakültesi, Orcid: 0000-0003-0281-3892 


\section{Giriş}

Haber tüketimi, toplumsal farkındalığı ve bireyin dünya görüşünü güçlü ve önemli ölçüde etkileme potansiyeline sahiptir (Keum, Devanathan, Deshpande, Nelson ve Shah, 2004, s. 371). Geleneksel gazetecilik bağlamında, güvenilir haber; "kaynağın olaya hâkim oluşu” şeklinde tanımlanmaktaydı. Ancak Web 2.0'nin artan popülaritesi ve gazete tirajındaki keskin düşüş, yeni medyanın geleneksel haber ve bilgi kaynaklarının yerini almasına neden oldu (Ahlers, 2006, s. 29). Bu değişen medya ortamında kullanıcılar bilgi sağlayan zengin bir kaynak çeşitliliğinin yanında, daha karmaşık haber çeşitliliğiyle karşı karşıya kalmaktadır. Çevrimiçi alanda kapı bekçileri ise insan müdahalesi olmadan algoritmalar tarafından çalıştırılan, haber toplayııı sitelerdir (Kang, Keunmin, Shaoke ve Sundar, 2011, s. 720). Dijital siteleri kullananların, tesadüfen habere maruz kalma potansiyeli katlanarak artmaktadır (Toff ve Nielsen, 2018, s. 638). Artık daha fazla insan, doğrudan haberin kaynağına gitmekten ziyade, arama motorları veya sosyal medya aracılı̆̆ıla çevrimiçi haberlere ulaşmaktadır. Newman, Fletcher, Kalogeropoulos, Levy ve Nielsen'nin (2017) yaptıkları çalışmada ankete katılanların üçte ikisinin -özellikle daha genç medya kullanıcıları ve habere ilgi duymayanların- haberlere çevrimiçi ulaştıklarını tespit etmiştir. Haber medyasının tüketimini etkileyen en belirgin faktör, akıllı telefon, tablet gibi mobil cihazların kolay erişilebilir ve ucuz olmasıdır. Mobil araçlar sayesinde kişiler alış-veriş yaparken, trafikte beklerken bir uygulamanın bildirilerine ya da bir haberin manşetlerine göz gezdirebilmektedir. Bununla birlikte tüketiciler, özellikle de genç kullanıcılar çeşitli platformlarda güncel olaylara çok fazla maruz kalarak, yanlış ve gerçek bilginin ayırt edilmesi anlamında seçici olamamaktadır (Marchi, 2012, s. 253). Mindich (2005) çalışmasında, 30 yaşın altındaki kişilerin \% 80' inin günlük gazete okumadıklarını, yaşlıların \% 70' inin ise mutlaka her gün en az bir günlük gazete okuduğunu, TV haber izleyicilerinin ortalama yaşının 60 olduğunu ve gençlerin haber tüketiminde düşüşler gösterdiğini dolayısıyla bu durumun, demokrasinin geleceğini karamsarlığa sürükleyebileceğini ifade etmektedir.

Yirminci yüzyılın ikinci yarısında yayıncılar, gazeteler ve daha sonra medya kuruluşlarının web siteleri şeklinde hiyerarşik bir haber tüketimi uygulamaları vardı. Okuyucular bilgiye doğrudan bu kanallar aracılığıyla ulaşmaktaydı. 1980'lerde, 24 saat yayın yapan kablolu televizyonun ortaya çıkışı ve web' in 1990'ların ortalarında ticarileşmesi haber alma rejiminin dengesizleşmesine neden oldu. Bu dengesizleşme yirmi birinci yüzyıl insanının Google gibi arama motorları, WhatsApp gibi mesajlaşma uygulamaları ve Facebook gibi sosyal medya ortamlarıyla hızlı ve dağınık bilgilere ulaşmasını sağlamaktadır (Nielsen ve Ganter, 2017, s. 1601). İzleyici analizi şirketi Parse.ly'in 2018'deki üç aylık çalışmasında, yayıncılara yönlendirilen tüm bilgi akışının yaklaşık \%82'sinin Google ve Facebook tarafından oluşturulduğu sonucuna ulaşılmıştır (PublishersDAILY, 2018). Bu bağlamda, sosyal paylaşım sitelerinin tesadüfi olarak kullanıcılarını habere maruz bırakma olasılıkları giderek artmaktadır. Çevrimiçi gazetelere doğrudan erişim yerine sosyal ağlar aracılığıyla habere daha hızlı ve kolay erişim, kullanıcılara düşük kontrol sağlamakta ve sıradan haberlerin bile yanlışlıkla önemli bilgilere dönüşmesine neden olmaktadır (Bergström ve Belfrage, 2018, s. 585).

Geleneksel haber kaynaklarından uzaklaşarak, sosyal medyada tesadüfi haber tüketmek, özellikle genç yetişkinler arasında giderek artmaktadır. Metzger, Flanagin, Markov, Grossman ve Bulger'in 2015 yılında yaptıkları çalışmaya göre, çevrimiçi haberlerin doğru okunması ile yaş arasında pozitif bir ilişki olduğu ortaya çıkmıştır. Buenos Aires'te yapılan bir araştırmaya 
göre, 29 yaş veya daha genç olan katılımcıların \%74'ü, haber almak için çevrimiçi haber sitelerini ziyaret etmek yerine, sosyal medyadayken haberle karşılaştıklarını ifade etmektedir. $\mathrm{Bu}$ sonuçlar, genç kullanıcıların haber aramak yerine, haberle karşılaştıkları ve bunu sosyal medyada yaşamanın bir parçası olarak yaptıkları savını doğrulamaktadır (Boczkowski, Mitchelsteın ve Matassı, 2017, s. 1785). Birçok kullanıc1, haberlere sosyal medyada arkadaşlarının paylaşımları üzerinden rastlamaktadır. Facebook kullanıcılarının üçte ikisi, Facebook'u haber almak için kullanmaktadır (Shearer ve Gottfried, 2017). Costera Meijer (2007) 450 Hollandalı gencin medya deneyimlerine odaklandığı çalışmasında, gençlerin medya üzerinden rastladıkları haberleri araştırdıklarını ve haberin haberi üzerine "atıştırma" yaparak, geniş bir konu yelpazesinin yüzeysel bilgilerini kazandıklarını, yaşlı insanların ise daha az sayıda konu hakkında derinlemesine bilgi almayı tercih ettiği sonucuna ulaşmıştır.

\section{Bilişsel Arabuluculuk Modeli ve Çevrimiçi Haber Aracılığıyla Öğrenme}

Kullanıcılar çevrimiçi ortamları, (Facebook ve Twitter gibi sosyal ağlarda gezinme, önceki kullanımlara dayalı algoritmalar aracılı̆̆ılla ağların kendileri tarafından otomatik olarak önerilmesi gibi) başka amaçlarla kullanırken, haber içeriğine tesadüfen maruz kalmaktadır. Çevrimiçi olarak çok sayıda bilgi kaynağıyla karşı karşıya kalan kullanıcılar, bilişsel çabayı en aza indirgeme ve tesadüfi kullanım üzerinden zaman baskısını hafifletme eğilimindedirler (Metzger, Flanagin ve Medders, 2010, s. 434). Sosyal medyaya giderek artan güven, kişilerin medya uygulamalarını gelenekselden dijitale doğru değiştirmesine neden olmaktadır (Hirsch, 2018, s. 230). Lo ve Chang (2006) yaptıkları çalışmada haberi araştıran kişilerin haber sürecine radyo, televizyon ve sosyal medya gibi medya araçlarından rastlayanlara göre daha fazla dahil olduklarını ifade etmişlerdir.

Haberlere maruz kalmak, haberlerin "öğrenildiği” anlamına gelmez. Haberin öğrenilmesi, bilişsel akıl yürütmeye bağlıdır. Haber kullanım motivasyonları ve siyasi bilgi arasındaki ilişkinin bilişsel sürecini açıklayan Eveland'in (2001) bilişsel arabuluculuk modeli (Cognitive Mediation Model-CMM), geçmiş deneyimler ve bilgilerle bilişsel bağlantılar kurmayı ve haberlerden yeni anlamlar çıkarmayı içeren bir akıl yürütme davranışı olarak haberin incelenmesini önermektedir. Bilişsel Arabuluculuk Modeli edebiyattan, psikolojiye ve medya ve iletişim araştırmalarına kadar kullanılan bir modeldir (King, Jensen, Carcioppolo, Krakow ve Sun, 2015; Lee, 2012; Zhao, Leiserowitz, Maibach and Roser-Renouf, 2011). Bilişsel arabuluculuk modeline göre, bilgi edinmek için öğrenme motivasyonları önemlidir ve haberlerden öğrenme sürecinin ilk başlangıç noktasını da öğrenme isteği oluşturmaktadır. Dijital dünya, haber tüketicisi kavramını "habere rastlayanlar/maruz kalanlar" ve "haber arayanlar" olarak farklılaştırmıştır. Sosyal medya kullanıcıları, çeşitli bakış açıları ve kaynaklardan haberlere bilerek ve tesadüfen maruz kalmakta (Yoo ve Zúñiga, 2014, s. 37) ve bu nedenle geleneksel haber kanallarına ulaşma isteği duymamaktadırlar.

$\mathrm{CMM}^{\prime}$ de öğrenme isteği, haberlerin içeriğini alıcıların bilincine getirdiği için ayrıntılı işlemede öncelikli olarak kabul edilmektedir. Bilişsel arabuluculuk modelinde ifade edildiği gibi habere maruz kalma, bilinçli yürütülen aktif bir sürecin (haber içeriğinin ne zaman, nerede ve nasıl kullanacağına karar verme), pasif hale gelmesine neden olmaktadır (Barthel ve Shearer, 2015). Dolayısıyla aktif haber arayışı, öğrenme sürecinde hayati bir rol oynamaktadır (Mihailidis ve Cohen, 2013, s. 6). Ancak sosyal medya sitelerinde habere rastladıktan sonra, haberleri okuyup, izlemekle yetinmeyen kullanıcılar, aynı zamanda içeriklerle kendi hikayelerini yeniden birleştirmekte, yorumlarını çevrimiçi olarak yayınlamakta ve çok sayıda sosyal medya kullanıcısı ile paylaşmaktadırlar. CS Lee ve Ma (2012), haberi paylaşmak, içeriğe 
yorumda bulunmak gibi bilgi arama motivasyonlarının, kullanıcıları sosyal medyadaki haber içeriğine dahil ettiğini ifade etmektedir. Habere ulaşmak için kullanılan sosyal medya uygulamaları, habere olan ilginin artmasına ve haberin detaylı bir şekilde işlenmesini sağlamaktadır. Sosyal medyada haber tüketimi geleneksel medyadan daha fazla rastlantısal olmasına rağmen, haber içeriğine ulaşma, yanıt verme ve içerik hakkında tartışma anlamında kullanıcısına daha fazla firsat sunmaktadır (Bode, 2016, s. 25). Dolayısıyla sosyal medyadaki haber içeriği ile etkileşimin, sitelerin hem aktif hem de tesadüfi olarak haber tüketimi için kullanıldığında bilişsel ayrıntılandırma ile nasıl bir ilişki içerisinde olduğu araştırılması gereken bir konu olarak karşımıza çıkmaktadır. İnsanların kaynak bulma şeklini değiştiren yeni dijital rakipler (bloglar, sosyal paylaşım siteleri, haber toplayıcılar vb.) haber kuruluşlarının görünürlüğünü azaltmış (Fletcher ve Park, 2017, s. 1284) ve bilginin artık belirli bir platforma bağlı kalmadan devinimini hızlandırmıştır. Bu bağlamda çalışma, gençlerin dijital olarak nasıl bilgilendirildiğini haberlerin aranması, sosyal medyada habere rastlantısal maruz kalınması, paylaşılan haber içeriğine katılım, bilişsel ayrıntılandırma ve güncel olaylar bilgisi arasındaki ilişkileri araştırmaktadır. Bu amaç doğrultusunda şu araştırma sorularına yanıt aranmaktadır; "Sosyal medya güncel olaylarla ilgili bilgilerin kazanılmasını nasıl etkiler? "Sosyal medyada haber içeriğine rastlantısal maruz kalma ile detaylandırma arasındaki ilişki nedir?" ve "Tesadüfi habere maruz kalma ile bilgi arasındaki ilişkiye katılım ve detaylandırma aracllı eder mi?"

\section{Yöntem}

\section{Evren ve Örneklem}

Gençlerin haber tüketimlerini çeşitli değişkenler bağlamında inceleyen bu araştırma Eveland'in (2001) bilişsel arabuluculuk modeli çerçevesinde desenlenmiştir. Çalışmanın evrenini Türkiye'de örgün eğitim gören üniversite öğrencileri oluşturmaktadır. YÖK verilerine göre 2018-2019 öğretim yılında örgün eğitim gören öğrenci sayıs1 4.785.215'dir. Bu ana kütlenin tamamına ulaşmak mümkün olmadığından kolayda örnekleme yöntemi uygulanmıştır ve katılımcılarla yüz yüze anket çalışması yapılmıştır. Bu araştırmanın çalışma grubunu erişim kolaylığı sebebiyle seçilen Anadolu Üniversitesi, Atatürk Üniversitesi, Gümüşhane Üniversitesi, Selçuk Üniversitesi, Erciyes Üniversitesi, Trabzon Teknik Üniversitesi ve Karabük Üniversitesi olmak üzere toplam yedi üniversiteden, 18-35 yaş aralığındaki gelişmekte olan yetişkinler arasından gönüllü olarak katılım sağlayan 402 katılımcı oluşturmaktadır. Örneklem büyüklüğü \% 5 güven aralığı düzeyine göre $n=384$, olarak hesaplanmıştır (Cohen vd., 2002, s. 94). Araştırmada toplam 402 kişiye anket uygulandığından örneklemin evreni temsil ettiği varsayılmıştır. Araştırmaya sadece 18 yaşın üzerindeki katılımcılar dâhil edilmiştir. Araştırmaya katılan 402 katılımcının \%49,8'i kadın $(n=200)$ ve \%50,2'si erkektir ( $n=202)$. Katılımcıların \%77,6'sı 18-22 yaş $(n=312), \% 22,4$ 'ü 23-32 yaş grubundadır $(\mathrm{n}=90)$.

\section{Veri Toplama Araçları}

Araştırmada veri toplama aracı olarak dört bölümden oluşan anket formu kullanılmıştır. Veri toplama aracının ilk bölümünde katılımcıların gün içinde en çok tercih ettiği iletişim aracı, sosyal medya araçlarını kullanım sıklığı, sosyal medya araçlarını kullanım amacı ve haberlere ulaşım kanalı bilgilerinden oluşan sosyal medya kullanımı bilgi formu yer almaktadır. Araştırma sorularının yanıtlanabilmesi için yüzyüze anket formundan yararlanılmıştır. Bu anket formunda demografik bilgiler, Sosyal Medya Araçlarını Kullanım Amacı, Sıklığı ve 
Habere Ulaşım Ölçeği (Eldorf-Hirsch, 2018) ve Sosyal Medyada Haberi Detaylandırma Ölçeği (Park ve Kaye 2019) kullanılmıştır. Sosyal Medyada Haber Detaylandırma Ölçeği beşli likert tipinde (1:kesinlikle katılmıyorum, 5: kesinlikle katılıyorum) 8 madde yer almaktadır. İfadelerin her biri sosyal medyada güncel olaylarla ilgili haberleri nasıl takip ettiğine ilişkin bilgileri toplamayı amaçlamaktadır. Bu çalışmada Cronbach Alpha katsayısı 0,77 olarak tespit edilmiştir. Anket formunun üçüncü bölümünde katılımcıların güncel olay bilgisini ölçmek amacıyla araştırmacı tarafından geliştirilen "Güncel Olay Bilgisi Testi” yer almaktadır. Testte güncel olaylara ilişkin 8 soru sorulmuş ve bu soruları "doğru" veya "yanlış" şeklinde cevaplamaları istenmiştir. Her soruda verilen cevabın gerçek cevabına göre doğru cevaplar 1 , yanlış cevaplar 0 olarak kabul edilmiştir. Elde edilen toplam puan en düşük 0 , en yüksek 8 olmaktadır. Bu çalışmada Cronbach Alpha katsayısı 0,93 olarak tespit edilmiştir. Veri toplama aracının dördüncü bölümünde katılımcıların cinsiyet, yaş, öğrenim durumu, medeni durumu, aylık gelir durumu bilgilerinden oluşan kişisel bilgi formu yer almaktadır.

\section{Verilerin Toplanması ve Analizi}

Veri toplama aşamasında öğrencilere araştırmanın amacı ve kapsamı anlatılmış, araştırmaya katılmayı kabul edenlere anket çalışması yapılmıştır. Tam olarak doldurulmayan anketler çalışmaya dahil edilmemiştir. Verilerin analizinde SPSS (Statistical Package Program for Social Science) 16.0 programı kullanılmıştır. Katılımcıların sosyal medya kullanımı ve demografik bilgileri frekans ve yüzde tablosunda sunulmuştur. Sosyal medyada güncel olayları takip şekline ilişkin sorular ortalama ve standart sapma tablosunda; güncel bilgi düzeyi her soru için doğru cevap toplamı olarak; güncel bilgi düzeyi toplam puanı ortalama ve standart sapma olarak gösterilmiştir. Sosyal medyada güncel olayları takip şekline ilişkin sorular ile güncel bilgi düzeyi toplam puanı arasındaki ilişkide Pearson korelasyon testinden yararlanılmıştır. Analizlerde güven aralığı (anlamlılık düzeyi) 0,05 olarak kabul edilmiştir.

\section{Bulgular}

Tablo 1. Katılımcıların Demografik Özelliklerine Göre Dağılımı

\begin{tabular}{llll}
\hline Demografik Değişken & Gruplar & $\mathbf{n}$ & \% \\
\hline \multirow{2}{*}{ Cinsiyet } & Kadın & 200 & 49,8 \\
& Erkek & 202 & 50,2 \\
\hline \multirow{2}{*}{ Yaş } & $18-22$ yaş & 312 & 77,6 \\
& 23-32 yaş & 90 & 22,4 \\
\hline \multirow{2}{*}{ Medeni durum } & Evli & 9 & 2,2 \\
& Bekar & 383 & 97,8 \\
\multirow{3}{*}{ Öğrenim durumu } & Ön lisans & 11 & 2,7 \\
& Lisans & 382 & 95,0 \\
& Lisansüstü & 9 & 2,2 \\
\hline \multirow{2}{*}{ Aylık gelir } & 450TL ve altı & 11 & 2,7 \\
& 451-1000TL & 378 & 94,0 \\
& 1001Tl ve üstü & 13 & 3,2 \\
\hline
\end{tabular}


Tablo 1'de katılımcıların demografik özelliklerine göre frekans ve yüzde dağılımı gösterilmiştir. Araştırmaya katılan 402 katılımının \%49,8'i kadın, \%50,2'si erkektir. Katılımcların \%77,6'sı 18-22 yaş, \%22,4'ü 23-32 yaş grubundadır. Katılımcıların \%2,2'si evli, \%97,8'i bekardır. Katılımcıların \%2,7'si ön lisans, \%95'i lisans, \%2,2'si lisansüstü düzeyde öğrenim görmüştür. Katılımcıların \%2,7'sinin aylık geliri 450TL ve altı, \%94'ünün 451-1000TL, \%32,'sinin aylık geliri 1001TL ve üstüdür.

Tablo 2. Sosyal Medya Araçlarının Kullanımına Göre Dağılım

\begin{tabular}{|c|c|c|c|}
\hline & Gruplar & $\mathbf{n}$ & $\%$ \\
\hline \multirow{6}{*}{$\begin{array}{l}\text { Gün içerisinde en çok kullanılan } \\
\text { iletişim aracı } \\
\text { (N=933) }\end{array}$} & Haber siteleri & 151 & 16,2 \\
\hline & Gazete & 45 & 4,8 \\
\hline & Sosyal medya & 380 & 40,7 \\
\hline & Televizyon & 78 & 8,4 \\
\hline & Arama motoru & 185 & 19,8 \\
\hline & E-posta & 94 & 10,1 \\
\hline \multirow{2}{*}{$\begin{array}{l}\text { Sosyal medya araçlarını } \\
\text { kullanma sıklığı }\end{array}$} & Haftada bir & 32 & 8,0 \\
\hline & Günde birkaç kez & 370 & 92,0 \\
\hline \multirow{4}{*}{$\begin{array}{l}\text { Sosyal medya kullanım amacı } \\
(\mathrm{N}=1023)\end{array}$} & Haber bilgi edinme & 315 & 30,8 \\
\hline & İletişim kurma & 266 & 26,0 \\
\hline & Eğlence & 285 & 27,9 \\
\hline & Alışveriş & 157 & 15,3 \\
\hline \multirow{4}{*}{$\begin{array}{l}\text { Haberlerin alındığı iletişim aracı } \\
(\mathrm{N}=694)\end{array}$} & Basılı gazete & 26 & 3,7 \\
\hline & Televizyon & 158 & 22,8 \\
\hline & Çevrimiçi internet siteleri & 210 & 30,3 \\
\hline & Sosyal medya paylaşımları & 300 & 42,3 \\
\hline
\end{tabular}

Tablo 2'de katılımcıların sosyal medya araçlarını kullanımına göre frekans ve yüzde dağılımı gösterilmiştir. Tablo 2 incelendiğinde, katılımcıların \%40,7'si gün içerisinde en çok sosyal medyayı, \%19,8'i arama motorlarını, \%16,2'si haber sitelerini, \%10,1'i e-posta, \%8,4'ü televizyon, \%4,8'i gazeteyi tercih etmektedir. Bir sonraki adım, sosyal medyanın kullanım amacı ve kullanılma sıklığıydı. Katılımcıların \%3,7'si sosyal medya araçlarını haftada bir, \%92'si günde birkaç kez kullanmaktadır. Katılımcıların \%30,8'i sosyal medyayı haber/bilgi edinme amaciyla, \%26'sı iletişim kurma, \%27,9'u eğlence, \%15,3'ü alışveriş amacıyla kullanmaktadır. Bir diğer aşama da haber kullanıcılarının tercih ettiği aracı belirlemekti. Katılımcların \%42,3'ü haberleri sosyal medya paylaşımlarından almakta, \%30,3'ü çevrimiçi internet sitelerinden, \%22,8'i televizyondan, \%3,7'si basılı gazetelerden almaktadır. 
Tablo 3. Sosyal Medyadan Alınan Güncel Olay Bilgilerinin Doğruluğuna İlişkin Betimsel İstatistikler

\begin{tabular}{|c|c|}
\hline Ölçek ve Alt Boyut & $\begin{array}{l}\text { Doğru } \\
\text { Cevap } \\
\%\end{array}$ \\
\hline 1. Türkiye F35 uçakları konusunda Amerika ile görüşmelerini sürdürmektedir & 73,9 \\
\hline 2. 2019’da Uluslararası Emmy ödülünü alan Türk tiyatrocu Serra Yılmazdır. & 78,9 \\
\hline 3. 2019 'da Türkiye'de yeni bir siyasi parti kuracak kişi Bülent Arınç'tır. & 74,1 \\
\hline $\begin{array}{l}\text { 4. Türkiye'de en son işlenen kadın cinayetleri arasında ölen kadınlardan birinin ismi } \\
\text { Emine Bulut'tur. }\end{array}$ & 80,3 \\
\hline 5. 2019 yılında emeklilik yasasına karşı protestoların yaşandığı ülke İngiltere'dir. & 72,6 \\
\hline 6. Sabah gazetesinin yeni genel yayın yönetmeni Ahmet Hakan olmuştur. & 67,9 \\
\hline 7. İngiltere'nin Avrupa Birliği'nden ayrılma çabasına Birexit denmektedir. & 70,9 \\
\hline $\begin{array}{l}\text { 8. Türkiye, } 2019 \text { Nobel ödülünü alan Avusturyalı yazar Peter Handke'yi, Bosna'daki } \\
\text { soykırımı inkar etmesi nedeniyle protesto etmiştir. }\end{array}$ & 71,6 \\
\hline DOĞRU CEVAP ORTALAMASI (Ort. $\pm S S$ ) & $5,90 \pm 2,88$ \\
\hline
\end{tabular}

Tablo 3'te sosyal medyadan alınan bilgilerin doğruluğuna ilişkin frekans, yüzde ve toplam puanlardan oluşan betimsel istatistiklerine yer verilmiştir. Sosyal medyadan alınan bilginin doğruluğuna yönelik sorulan soruların yedisine katılımcıların \%70'ten fazlasının, bir soruya \% 67,9'unun doğru cevap verdiği; güncel olay bilgi düzeyinin $(5,90 \pm 2,88)$ yüksek düzeyde olduğu tespit edilmiştir.

Tablo 4. Sosyal Medyada Güncel Olayları Takip Şekline İlişkin Betimsel İstatistikler

\begin{tabular}{|c|c|c|}
\hline & $\overline{\mathbf{X}}$ & SS \\
\hline 1. Arkadaşlarımın ve ailemin gündemle ilgili yaptıkları yorumları okurum. & 3,56 & 1,17 \\
\hline $\begin{array}{l}\text { 2. Takip ettiğim veya abone olduğum haber kuruluşların veya bireysel gazetecilerin } \\
\text { gündemle ilgili haber paylaşımlarını okudum. }\end{array}$ & 3,73 & 1,10 \\
\hline $\begin{array}{l}\text { 3. Takip ettiğim veya abone olduğum diğer kurumların veya kişilerin gündemle ilgili } \\
\text { haber paylaşımlarını okudum. }\end{array}$ & 3,82 & 1,08 \\
\hline $\begin{array}{l}\text { 4. Sosyal medyadaki gündemle ilgili haberlerde karşılaştı̆̆ım şeyler hakkında sık sık } \\
\text { kendimi düşünürken buluyorum. }\end{array}$ & 3,46 & 1,08 \\
\hline $\begin{array}{l}\text { 5. Sosyal medyada çıkan haberlerde karşılaştığım olayları kendi kişisel } \\
\text { tecrübelerimle ilişkilendirmeye çalışırım. }\end{array}$ & 3,57 & 1,06 \\
\hline 6. Başkalarının okuması için güncel bir haber özeti yazdım ve yayınladım. & 2,67 & 1,35 \\
\hline $\begin{array}{l}\text { 7. Gündemdeki yeni olayları içeren linkleri, kendi düşüncelerimle veya haberler } \\
\text { hakkındaki yorumlarımla birlikte paylaştım. }\end{array}$ & 2,99 & 1,25 \\
\hline 8. Okuduğum haberlere cevap olarak yorum, soru veya bilgi gönderdim. & 3,27 & 1,29 \\
\hline
\end{tabular}

1: Kesinlikle katılmiyorum 5: Kesinlikle katılıyorum 
Tablo 4'te sosyal medyayı kullanım şekline ilişkin betimsel istatistiklerine yer verilmiştir. Katılımcıların sosyal medya kullanım şekli incelendiğinde "takip ettiği veya abone olduğu haber kuruluşları veya bireysel gazetecilerin gündemle ilgili haber paylaşımlarını okuma" $(3,73 \pm 1,10)$, "takip ettiği veya abone olduğu diğer kurumların veya kişilerin gündemle ilgili haber paylaşımlarını okuma" $(3,82 \pm 1,08)$ davranışlarının en yüksek düzeyde olduğu tespit edilmiştir. Diğer sosyal medya kullanım şekli sırasıyla "sosyal medyada çıkan haberlerde

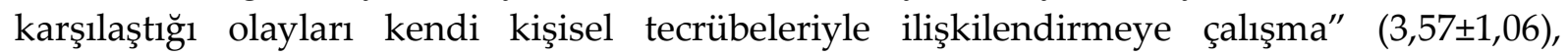
"arkadaşlarının ve ailesinin gündemle ilgili yaptığı yorumları okuma" $(3,56 \pm 1,17)$ olduğu tespit edilmiştir.

Tablo 5. Sosyal Medyada Aktif/Tesadüfi Olarak Haberle Karşılaşma İle Güncel Olay Bilgi Düzeyi Arasındaki İlişkiye Ait Korelasyon Analizi

\section{Bilgi Düzeyi}

(r)

\begin{tabular}{lc}
\hline $\begin{array}{l}\text { 1. Arkadaşlarımın ve ailemin gündemle ilgili yaptıkları yorumları okurum. } \\
\text { 2. Takip ettiğim veya abone olduğum haber kuruluşların veya bireysel gazetecilerin }\end{array}$ & $0,44^{* *}$ \\
gündemle ilgili haber paylaşımlarını okudum. & $0,44^{* *}$ \\
\hline $\begin{array}{l}\text { 3. Takip ettiğim veya abone olduğum diğer kurumların veya kişilerin gündemle ilgili } \\
\text { haber paylaşımlarını okudum. }\end{array}$ & $0,17^{* *}$
\end{tabular}

4. Sosyal medyadaki gündemle ilgili haberlerde karşılaştığım şeyler hakkında sık sık kendimi düşünürken buluyorum.

5. Sosyal medyada çıkan haberlerde karşılaştığım olayları kendi kişisel tecrübelerimle ilişkilendirmeye çalışırım.

$0,28^{* *}$

\begin{tabular}{lc}
\hline 6. Başkalarının okuması için güncel bir haber özeti yazdım ve yayınladım. & $0,11^{*}$ \\
\hline $\begin{array}{l}\text { 7. Gündemdeki yeni olayları içeren linkleri, kendi düşüncelerimle veya haberler } \\
\text { hakkındaki yorumlarımla birlikte paylaştım. }\end{array}$ & $0,11^{*}$ \\
\hline \begin{tabular}{l} 
8. Okuduğum haberlere cevap olarak yorum, soru veya bilgi gönderdim. \\
\hline
\end{tabular} & $-0,16^{* *}$ \\
\hline
\end{tabular}
${ }^{*} \mathrm{p}<0,05{ }^{* *} \mathrm{p}<0,01$

Tablo 5'te sosyal medyada güncel olayları takip şekli ile güncel olay bilgi düzeyi arasındaki ilişkiye ait Pearson korelasyon analizi sonuçlarına yer verilmiştir. Arkadaşları ve ailesinin gündemle ilgili yaptıkları yorumları okuma $(\mathrm{r}=-0,58 ; \mathrm{p}<0,05)$, takip ettiği/abone olduğu haber kuruluşlarının gündemle ilgili haber paylaşımlarını okuma $(\mathrm{r}=-0,48 ; \mathrm{p}<0,05)$, takip ettiği/abone olduğu diğer kurumların gündemle ilgili haber paylaşımlarını okuma $(r=-0,58 ; p<0,05)$, sosyal medyadaki gündemle ilgili karşılaştığ 1 şeyler hakkında sık sık kendini düşünürken bulma ( $\mathrm{r}=-$ $0,58 ; \mathrm{p}<0,05)$, başkalarının okuması için güncel bir haber özedi yazma/yayınlama $(\mathrm{r}=-0,58$; $\mathrm{p}<0,05)$, gündemdeki yeni olayları içeren linkleri, kendi düşünceleri ve haber hakkındaki yorumlarıyla birlikte paylaşma $(\mathrm{r}=-0,58 ; \mathrm{p}<0,05)$ sıklığı ile bilgi düzeyi puanları arasında pozitif yönlü ve anlamlı ilişki tespit edilmiştir. Arkadaşları ve ailesinin gündemle ilgili yaptıkları yorumları okuma, takip ettiği/abone olduğu haber kuruluşlarının gündemle ilgili haber paylaşımlarını okuma, takip ettiği/abone olduğu diğer kurumların gündemle ilgili haber paylaşımlarını okuma, sosyal medyadaki gündemle ilgili karşılaştı̆̆ 1 şeyler hakkında sık sık kendini düşünürken bulma, başkalarının okuması için güncel bir haber özedi 
yazma/yayınlama, gündemdeki yeni olayları içeren linkleri, kendi düşünceleri ve haber hakkındaki yorumlarıyla birlikte paylaşma sıklığı yüksek olan katılımcıların güncel olaylara ilişkin bilgi düzeyi de yüksektir. Okuduğu haberlere cevap olarak yorum, soru veya bilgi gönderme puanı ile güncel olaylara ilişkin bilgi düzeyi arasında anlamlı ilişki tespit edilmiştir. Okuduğu haberlere cevap olarak yorum, soru veya bilgi gönderme siklığ1 yüksek olan katılımcıların güncel olaylara ilişkin bilgi düzeyi de yüksektir. Sosyal medyada çıan haberlerde karşılaştığı olayları kendi kişisel tecrübeleriyle ilişkilendirmeye çalışma puanları ile bilgi düzeyi puanları arasında anlamlı ilişki olmadığı tespit edilmiştir.

\section{Tartışma, Sonuç ve Öneriler}

Günümüz medya ortamında bilgi, internette serbestçe dolaşmaktadır. Böyle bir ortamda, kullanıclar da kendi yörüngelerini seçme ve bilgiyi istediği platformdan, istediği zamanda tüketme özgürlügüne sahip olmaktadır. Akıllı telefon, tablet gibi cihazların hızlı ve geniş yayılımı, haber medyasının tüketimini de etkilemektedir. Haberin her zaman ve herhangi bir yerde tüketilebilmesi, özellikle otuz yaşın altındaki çoğu insanın haber süreçlerine katılımlarını etkilemektedir (Holton, Coddington, Lewis ve de Zúñiga, 2015). Buna göre bu araştırmanın ilk bulgularında, gençlerin büyük çoğunluğunun (\%42,3'ü) haberleri sosyal medya üzerinden tüketmeleri, gençler arasında sosyal medya kullanımının yükselişinden kaynaklandığını destekler niteliktedir. Dünya nüfusunun \%45'i (3.5 milyar) aktif sosyal medya kullanıcısı ve Türkiye' de bu oran \%63 ve bir günlük sosyal medyada geçirilen ortama süre ise iki saat kırk altı dakikadır (WeAreSocial, 2019). Sosyal ağların kullanıcı taleplerini karşılama oranı arttıkça, bu ortamlara katılım potansiyelinde de artış yaşanmaktadır. Dolayısıyla geleneksel medya ortamları gibi gazeteciliğin de kendisini internete ve mobil hizmetlere duyarlı biçimlere dönüştürerek, yirmi birinci yüzyılın bilimsel gelişmişliğine ve hızlı yaşamına ayak uydurma çabasında olması kaçınılmaz bir son olarak görülebilir.

Gazetelere, televizyon haberlerine ve çevrimiçi haber sitelerine katılmanın bilgi edimini artırdığı kabul edilmiştir (Costera, 2015; Dimitrova, Shehata, Strömbäck ve Nord, 2014). Ancak literatürde sosyal medyanın da öğrenmeyi teşvik edip etmediği hakkında belirsizlikler devam etmektedir. Bazı çalışmalar kesintisiz bağlanabilirlik, bilgi bolluğu ve sürekli paylaşımın kullanıcılara bilgi edinme anlamında sayısız firsatlar sunduğunu ifade etmektedir (Sveningsson, 2015; Shearer ve Gottfried, 2017; Mitchell ve Page, 2015). Baz1 çalışmalar da, sosyal medyanın ağırlıklı olarak eğlence, sosyalleşme ve görsel sunum odaklı oldukları veya sahte haberler de dahil olmak üzere yanlış bilgilere maruz kalmayı teşvik ettikleri için bilgi kazanma anlamında faydalı olmadığını savunmaktadır (Shehata ve Strömbäck, 2018; Pasquale, 2015). Başkalarının hayatlarını takip etmenin ötesinde sosyal medya gittikçe artan bir şekilde haber materyallerine yer vermekte ve böylece kullanıcıların haber tüketimlerinin de bir parçası haline gelmektedir. Facebook, Twitter veya Instagram gibi sosyal ağlar, kullanıcısına dijital bilgilendirme anlamında yeni fırsatlar sunmaktadır. Sosyal medyanın haber tüketiminde oynayabileceği en yararlı rol, haber içeriğiyle etkileşime yönlendirme ve öğrenmeyi teşvik etmek adına zengin bir ortam sağlamasıdır (Shehata ve Strömbäck, 2018; Greenhow ve Reifman, 2009; Lee ve Ma, 2012). Araştırmanın bulgularında güncel olay bilgi düzeyine yönelik soruların yedisine katılımcıların \%70'ten fazlasının doğru cevap vermiş olması, sosyal medya kullanımı ile aktif olarak haber içeriği aramak ve haber içeriğine yanlışlıkla maruz kalmak arasında anlamlı bir ilişkinin olduğu, habere maruz kalan kişilerin bile sosyal medyada rastladıkları haberlere dikkat ettikleri soncuna ulaşılmıştır. 
Dolayısıyla elde edilen bu bulgular, sosyal medyanın bilgi edinme anlaminda firsatlar sunduğunu ifade eden çalışmaları (Sveningsson, 2015; Shearer ve Gottfried, 2017; Mitchell ve Page, 2015) desteklemektedir.

$\mathrm{Bu}$ araştırmada ayrıca sosyal medyadaki haber içeriğine tesadüfi maruz kalmak ile katılım ve güncel olayların bilgisi arasındaki ilişkiler incelenmiştir. Geleneksel haber medyası yerine sosyal medyadan haber almayı tercih eden kullanıcilar, özellikle kasıtlı haber arama ve haberlere erişimin yaygın bir yolu olduğu çevrimiçi web sitesi gibi uygulamalarla karşılaştırıldığında, rastlantısal haberlere daha yatkındır. Knoll, Matthes ve Heiss'e (2018) göre, insanlar gündemle ilgili bilgilere ihtiyaç duyduklarında, kasıtlı bir amaç ortaya çıkabilir. Haber aramaya daha az motive olanlar, interneti diğer amaçlar için kullanırken haber konularını keşfetmeyi ve bilgi edinmeyi sevdiklerini ve bu tür rastlantısal haber keşiflerine karşı genellikle olumlu tutumlara sahip olduklarını ifade ederler (Yadamsuren ve Erdelez, 2010). Sosyal medyada haber içeriğine rastlantısal olarak maruz kalanların da bu içerikle etkileşime girerek, öğrenebilecekleri düşünülebilir. Bu araştırma bulgularında, haberlerle daha az ilgilenen gençlerin bilişsel kazanımlarında, rastlantısal katılımın güçlü olduğu sonucuna varılmıştır. Sosyal medyada haber içeriğine rastlantısal olarak maruz kalanların da tıpkı aktif olarak arama yapıyormuş gibi etkileşime girmeleri ile (gündemdeki yeni olayları içeren linkleri, kendi düşünceleri ve haber hakkındaki yorumlarıyla birlikte paylaşma veya başkalarının okuması için güncel bir haber özeti yazma/yayınlama gibi) bilgi düzeyi puanları arasında pozitif yönlü ve anlamlı ilişki tespit edilmiştir. Gündemle ilgili haberleri beğenme, yorum yapma ve yeniden paylaşma gibi eylemlerle gerçekleştirilen etkileşimin, içerikle ilgili daha fazla bilişsel ayrıntıyı desteklediği söylenebilir. Bu bulgular sosyal medyada haber içeriğine aktif katılımın gündemle ilgili olaylar hakkında bilgi sahibi olmayı sağlayabileceği yönündeki araştırmaları desteklemektedir (Holt, Shehata, Strömbäck ve Ljungberg, 2013; Oeldorf-Hirsch ve Sundar, 2015). Habere tesadüfen maruz kalma ve içerikle ilgili detaylandırma arasındaki böyle bir bağlantı, motive olmuş haber kullanımına bağlı olan bilişsel arabuluculuk modeliyle doğrudan çelişmektedir. Yine de, sosyal medyanın sahip olduğu özellikler yoluyla haberlere katılımın, haber içeriği hakkında daha derin düşüncelerin tetiklenmesinde anahtar bir unsur olduğu düşünülebilir. Araştırmanın tüm sonuçları ele alındığında haberi arayan ve tesadüfi rastlayanlar arasında daha fazla bilgi gediğine yol açacağ1 endişesinin aksine (Bennett ve Iyengar, 2008), sadece aktif haber arayışının değil, yalnızca haber içeriklerine maruz kalınarak gerçekleştirilen katılımın da, bilişsel ayrıntılamayı olumlu yönde etkilediğini ve sosyal medya kullanımının çevrimiçi haber tüketiminde önemli olma olasılığını göstermesi açısından bu araştırmanın alanyazına katkı sağladığ1 görülmektedir. Bundan sonraki çalışmalarda ise çevrimiçi haber tüketiminin, kültürel farklılıklar üzerinde evrenselleştirici bir etkisinin olup olmadığ konusunun araştırılması önerilmektedir.

\section{Kaynakça}

Ahlers, D. (2006). News consumption and the new electronic media. Harvard International Journal of Press/Politics, 11 (1), 29-52. DOI: 1081180X05284317

Barthel, M., \& Shearer, E. (2015). How do Americans use Twitter for news. Pew Research Center, 1-7. Retrieved from https://www.pewresearch.org/fact-tank/2015/08/19/how-do-americans-use-twitterfor-news/

Bennett, W. L \& Iyengar, S. (2008). A new era of minimal effects? The changing foundations of political communication. Journal of Communication, 58, 707-731. DOI: 10.1111/j.1460-2466.2008.00410.x 
Bergström, A. \& Belfrage M. J. (2018). News in social media: incidental consumption and the role of opinion leaders. Digital Journalism, 6(5), DOI: 583-598. 10.1080/21670811.2018.1423625

Bode, L. (2016). Political news in the news feed: Learning politics from social media. Mass Communication and Society, 19(1), 24-48. DOI: 10.1080/15205436.2015.1045149

Boczkowsk1, P., Mitchelstein, E., \& Matass1, M. (2017). Incidental news: How young people consume news on social media. In proceedings of the 50th Hawaii International Conference on System Sciences. Retrieved from: https://scholarspace.manoa.hawaii.edu/handle/10125/41371

Cohen, M. A., James, N., \& Mihailidis, P. (2013). Exploring curation as a core competency in digital and media literacy education. Journal of Interactive Media in Education, 1-19. Retrieved from: https://jime.open.ac.uk/2013/02

Cohen, L., Manion, L., \& Morrison, K. (2002). Research methods in education. New York: Routledge Falmer

Costera M. I. \& Groot K. T. (2015). Checking, sharing, clicking and linking: Changing patterns of news use between 2004 and 2014. Digital Journalism, 3(5), DOI: 664-679. 10.1080/21670811.2014.937149

Costera M. I. (2007). The paradox of popularity: How young people experience the news. Journalism Studies, 8(1), 1-22. DOI: 10.1080/14616700601056874

Dimitrova, D. V., Shehata, A., Strömbäck, J., \& Nord, L. W. (2014). The effects of digital media on political knowledge and participation in election campaigns: Evidence from panel data. Communication Research, 41(1), 95-118. DOI: 10.1177/0093650211426004

Fletcher, R. \& Park, S. (2017). The Impact of Trust in the News Media on Online News Consumption and Participation. Digital Journalism, 5 (10), 1281-1299. DOI: 10.1080/21670811.2017.1279979

Greenhow, B. Y. C. \& Reifman, J. (2009). Engaging youth in social media: Is Facebook the new media frontier? Neiman Reports, 63(3), 53-55.

Holt, K., Shehata, A., Strömbäck, J. \& Ljungberg, E. (2013). Age and the effects of news media attention and social media use on political interest and participation: Do social media function as leveller? European Journal of Communication, 28(1), 19-34. DOI: 10.1177/0267323112465369

Holton, A. E., Coddington, M., Lewis, S. C. \& De Zúñiga, H. G. (2015) Reciprocity and the news: The role of personal and social media reciprocity in news creation and consumption. International Journal of Communication, 9 (22), 2526-2547.

Kang, H., Keunmin B., Shaoke Z. \& Sundar, S. S. (2011). Source cues in online news: Is the proximate source more powerful than distal sources?. Journalism \& Mass Communication Quarterly 88(4), 719736. DOI: $10.1177 / 107769901108800403$

Keum, H., Devanathan, N., Deshpande, S., Nelson, M. R., \& Shah, D. V. (2004). The citizen-consumer: Media effects at the intersection of consumer and civic culture. Political Communication, 21(3), 369391. DOI:10.1080/10584600490481479

King, A. J., Jensen, J. D., Carcioppolo, N., Krakow, M. M., \& Sun, Y. (2015). Comparing theories of media learning: cognitive mediation, information utility, and knowledge acquisition from cancer news. Mass Communication and Society, 18(6), 753-775. DOI:10.1080/15205436.2015.1027406

Knoll, J., Matthes, J. \& Heiss, R. (2018). The social media political participation model: A goal systems theory perspective. Convergence, 1-22. DOI:10.1177/1354856517750366

Lee, H. (2012). Communication mediation model of late-night comedy: The mediating role of structural features of interpersonal talk between comedy viewing and political participation. Mass Communication and Society, 15(5), 647-671. DOI:10.1080/15205436.2012.664239

Lee, C. S. \& Ma, L. (2012). News sharing in social media: The effect of gratifications and prior experience. Computers in Human Behavior, 28(2), 331-339. DOI: 10.1016/j.chb.2011.10.002

Lo, V. H. \& Chang, C. C. (2006). Knowledge about the Gulf Wars - A theoretical model of learning from the news. Harvard International Journal of Press-Politics, 11(3), 135-155. 
Newman, N., Fletcher, R., Kalogeropoulos, A., Levy, D. A., \& Nielsen, R. K. (2017). Reuters Institute digital news report. Oxford, England: Reuters Institute for the Study of Journalism, University of Oxford.

Nielsen, R. K., \& Ganter, S. A. (2017). Dealing with digital intermediaries: A case study of the relations between publishers and platforms. New Media $\mathcal{E}$ Society, 20(4), 1600-1617. DOI: $10.1177 / 1461444817701318$

Marchi, R. (2015). With Facebook, blogs, and fake news, teens reject journalistic "objectivity". Journal of Communication Inquiry, 36(3), 246-262. DOI: 10.1177/0196859912458700

Metzger, M., Andrew, J., Flanagin, J. \& Medders, R. B. (2010). Social and heuristic approaches to credibility evaluation online. Journal of Communication, 60 (3), 413-439. DOI: 10.1111/j.14602466.2010.01488.x

Metzger, M., Flanagin J., Markov A. J., Grossman A. R. \& Bulger, M. (2015). Believing the unbelievable: understanding young people's information literacy beliefs and practices in the United States. Journal of Children and Media, 9(3), 325-348. DOI: 10.1080/17482798.2015.1056817

Mindich, D. (2005). Tuned out-Why Americans under 40 don't watch the news. New York, NY: Oxford University Press.

Mitchell, A. \& Page, D. (2015). The evolving role of news on Twitter and Facebook. Pew Internet and American Life Project. Retrieved from www.journalism.org/files/2015/07/Twitter-and-News-SurveyReport-FINAL2.pdf.

Oeldorf-Hirsch, A., Sundar, S. S. (2015). Posting, commenting, and tagging: Effects of sharing news stories on Facebook. Computers in Human Behavior, 44, 240-249. DOI: 10.1016/j.chb.2014.11.024

Park, C. S. \& Kaye, B. K. (2019). Mediating roles of news curation and news elaboration in the relationship between social media use for news and political knowledge. Journal of Broadcasting $\mathcal{E}$ Electronic Media, 63(3), 455-473. DOI: 10.1080/08838151.2019.1653070

Pasquale, F. (2015). The black box society. Cambridge, MA: Harvard University Press.

PublisherDaily (2018). Report: Facebook is Primary Referrer For Lifestyle Content, Google Search Dominates Rest. Retrieved from https:/www.mediapost.com/publications/article/320542/report-facebook-isprimary referrer-for-lifestyle.html.

Shearer, E. \& Gottfried, J. (2017). News use across social media platforms 2017. Retrieved from http://www.journalism.org/2017/09/07/news-use-across-social-media-platforms-2017/.

Shehata, A. \& Strömbäck, J. (2018). Learning political news from social media: Network media logic and current affairs news learning in a high-choice media environment. Communication Research. DOI: 10.1177/0093650217749354

Sveningsson, M. (2015). It's only a pastime, really': Young people's experiences of social media as a source of news about public affairs. Social Media + Society, 1(2), 1-11. DOI: 10.1177/2056305115604855

Toff, B. \& Nielsen, R. K. (2018). I Just Google It: Folk Theories of Distributed Discovery. Journal of Communication, 68 (3), 636-657. DOI: 10.1093/joc/jqy009

WeAreSocial\&Hootsuite (2019). Digital $2019 . \quad$ Retrieverd from https://wearesocial.com/blog/2019/01/digital-2019-global-internet-use-accelerates.

Yadamsuren, B. \& Erdelez, S. (2010). Incidental exposure to online news. Proceedings of the American Society for Information Science and Technology, 47(1), 1-8. DOI: 10.1002/meet.14504701237

Yoo, W. S. \& Gill-de-Zúñiga, H. G. (2014). Connecting blog, Twitter and Facebook use with gaps in knowledge and participation. Communication \& Society, 27(4), 33-48. DOI: 10.15581/003.27

Zhao, X., Leiserowitz, A. A., Maibach, E. W. W Roser-Renouf, C. (2011). Attention to science/environment news positively predicts and attention to political news negatively predicts global warming risk perceptions and policy support. Journal of Communication, 61(4), 713-731. DOI: 10.1111/j.1460-2466.2011.01563.x 